\title{
Atrial Fibrillation Diagnosed through Sensory Complaints
}

\author{
Stefanie S. Thomassin, MD, MPH, and Steven Zinn, MD
}

Taste and smell disorders have multiple causes. We describe a patient in whom atrial fibrillation and subsequent embolic stroke was discovered because of complaints of decreased smell and taste. These deficits ultimately improved after treatment of the atrial fibrillation along with anticoagulation medication for stroke prevention. (J Am Board Fam Med 2014;27:570-574.)

Keywords: Atrial Fibrillation, Case Reports, Dysosmia

Taste and smell play an important role in daily life. Deficits in one of these senses can be extremely unpleasant and can affect caloric intake or one's ability to sense warning signs, such as toxins or smoke. Dysgeusia is the distorted ability to taste, whereas dysosmia is the distorted ability to smell. According to the National Institutes of Health, roughly 200,000 patients every year present with complaints of altered taste, and $1 \%$ to $2 \%$ of North Americans state they have a smell disorder. ${ }^{1,2}$ These symptoms can be a manifestation of local or systemic conditions. This case demonstrates a patient with a cardiovascular condition who presented with altered taste and smell and associated weight loss as the only reported symptoms.

\section{Case Presentation}

A 54-year-old man presented to his family physician's office with a 1-month history of decreased smell and change in taste. The patient noted difficulty smelling his coffee in the morning and described the taste of food as "rotten eggs." The unpleasant sensations caused him to limit his caloric intake to broth, yogurt, and juice, which led to a reported weight loss of 15 to

This article was externally peer reviewed.

Submitted 12 June 2013; revised 23 April 2014; accepted 28 April 2014.

From the Department of Family Medicine, Drexel University, Philadelphia, PA.

Funding: none.

Conflict of interest: none declared.

Corresponding author: Stefanie S. Thomassin, MD, MPH, Department of Family Medicine, Drexel University, 10 Shurs Ln, Philadelphia, PA 19127 (E-mail: stefaniethomassin@gmail.com).
$20 \mathrm{lb}$ over 6 weeks. He reported intermittent periods of nausea without vomiting and occasional heartburn. He tried a 14-day trial of omeprazole with minimal relief of heartburn and no improvement in appetite. The patient denied fevers, chills, chest pain, palpitations, shortness of breath, abdominal pain, diarrhea, headache, other neurologic symptoms, or any prior issues with taste or smell.

The patient's medical history was notable for testicular seminoma, for which he had received radiation and a unilateral orchiectomy in 1989, with no evidence of recurrence. The only other surgical history was a tonsillectomy. Medications included a daily multivitamin and the recent trial of omeprazole, which the patient completed. Allergies included tetracycline and Merthiolate tincture. The patient was not a smoker and denied excess alcohol consumption.

During physical examination, the patient was afebrile, had a pulse of 160 beats per minute (bpm) and a blood pressure of 104/90 $\mathrm{mmHg}$. He appeared fatigued and worried but in no acute distress. Head, eyes, ears, nose, and throat examination was unremarkable, with no visible nasal or oral lesions. Cardiac examination revealed an irregular rhythm, tachycardia, and no murmurs. Lung examination showed symmetric expansion with no abnormality upon percussion or auscultation. Neurologic examination was normal except for a diminished sense of smell, which was confirmed by his inability to identify coffee or tobacco. An electrocardiogram showed rapid atrial fibrillation at 180 bpm (Figure 1). 
Figure 1. Rapid atrial fibrillation seen on an electrocardiogram.

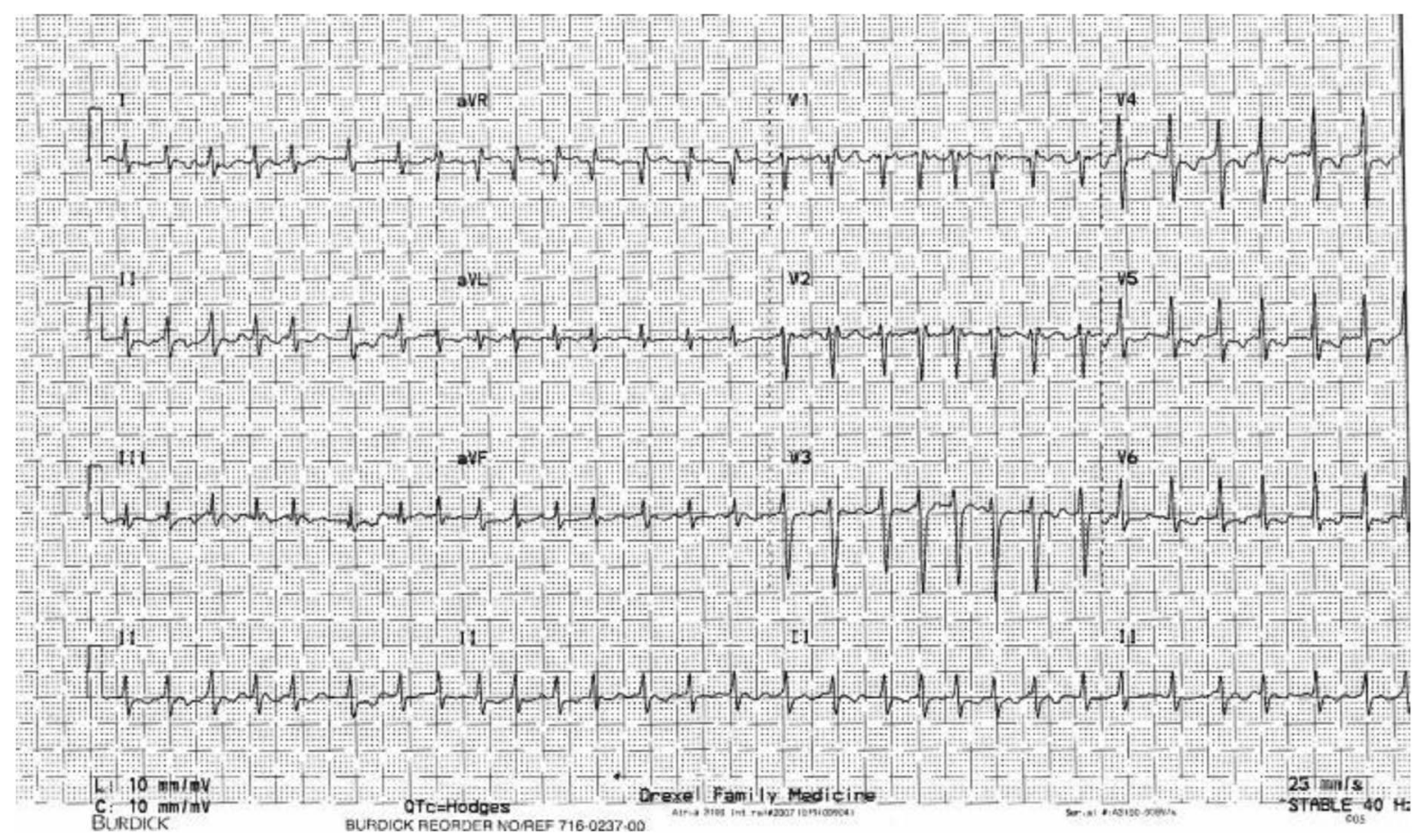

His family physician sent the patient to the emergency department, where vital signs and physical examination remained unchanged. Laboratory test results at admission showed a white blood cell count of $7300 / \mu \mathrm{L}$, hemoglobin $15.4 \mathrm{mg} / \mathrm{L}$, thyroid-stimulating hormone $2.430 \mu \mathrm{IU} / \mathrm{mL}$, troponin $0.02 \mathrm{ng} / \mathrm{mL}$, and normal electrolytes, liver function tests, and coagulation studies. A plain chest radiograph showed clear lungs.

The patient was started on a continuous infusion of diltiazem to control the rate of his atrial fibrillation. After a transesophageal echocardiogram showed an estimated left ventricular ejection fraction of $20 \%$ with no thrombus, the patient underwent external cardiac conversion. His cardiac rhythm was converted to sinus bradycardia at 50 bpm.

Magnetic resonance imaging of the brain showed subacute hemorrhagic infarcts in the left parietal lobe and in the right insular cortex (Figures 2 and 3). Magnetic resonance angiography showed the right distal middle cerebral arteries to be obscured due to laminar necrosis, whereas contrast-enhanced magnetic resonance angiography of the neck was unremarkable. An electroencephalogram showed no signs of seizure activity. The patient was given aspirin as per a recommendation from neurology with the further recommendation that warfarin could be started within a few weeks with close monitoring. The patient was discharged from the hospital with a LifeVest, aspirin $81 \mathrm{mg}$ daily, Lasix $20 \mathrm{mg}$ daily, amiodarone $200 \mathrm{mg}$ daily, digoxin 0.25 $\mathrm{mg}$ daily, metoprolol $75 \mathrm{mg}$ orally every 8 hours, magnesium gluconate $500 \mathrm{mg}$ orally every 12 hours, and sucralfate 3 times a day.

The patient was followed as an outpatient by family medicine, cardiology, and neurology. Following a discussion with neurology several weeks after discharge, the patient was started on oral anticoagulation because he had a CHADS score of 2 . The patient slowly regained his sense of taste and smell over the next 6 months, and his cardiac ejection fraction normalized as the rhythm of the atrial fibrillation was controlled. The patient was gradually able to increase his oral intake and regain the weight he had lost.

\section{Discussion}

A 54-year-old man with no known active medical problems came into an outpatient physician's office with profoundly altered taste and smell. Ultimately, the cause of the dysosmia and dysgeusia was atrial 
Figure 2. T1-weighted magnetic resonance imaging of the brain shows a subacute infarct in the right insular cortex.

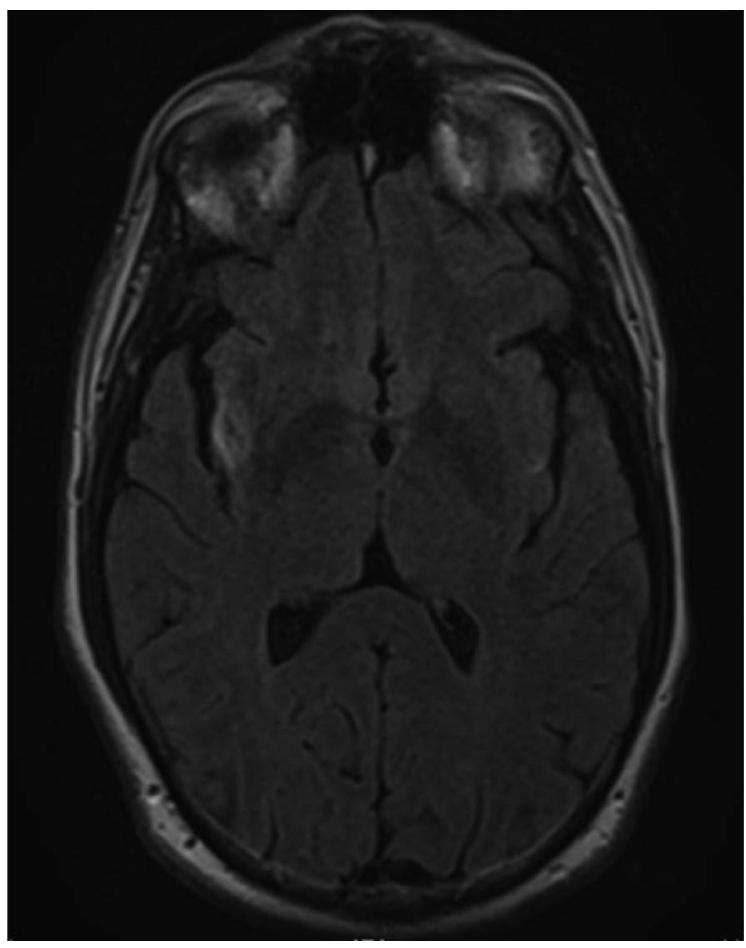

fibrillation with embolic infarcts in the right insula and left parietal regions of the cerebral cortex, which are known to be associated with taste and smell. Patients with dysosmia and dysgeusia often initially seek treatment from their primary care physician. It is important to know both common and uncommon causes of sensory deficits and their workup.

Smell and taste disorders are common. A recent study showed that $6.1 \%$ of 53 - to 59 -yearolds and $62.5 \%$ of 80 - to 97-year-olds suffer olfactory nerve impairment. ${ }^{3}$ Disorders of taste and smell are closely linked, and many patients with olfactory nerve damage may actually complain of taste changes. ${ }^{4}$

The sense of smell is transmitted by cranial nerves (CNs) I and V. CN I is responsible for qualitative odor sensations, for example, the "lemon" smell, whereas $\mathrm{CN} \mathrm{V}$ is responsible for the somatosensory overtones of odorants, for example, the warmth, coolness, or irritation of the odorant. The piriform cortex assesses chemical structure of the odorant and can help categorize it into categories such as "minty" or "woody." The amygdala plays a role in the emotional response to smells.
Figure 3. Magnetic resonance imaging of the brain shows a subacute infarct in the left parietal lobe.

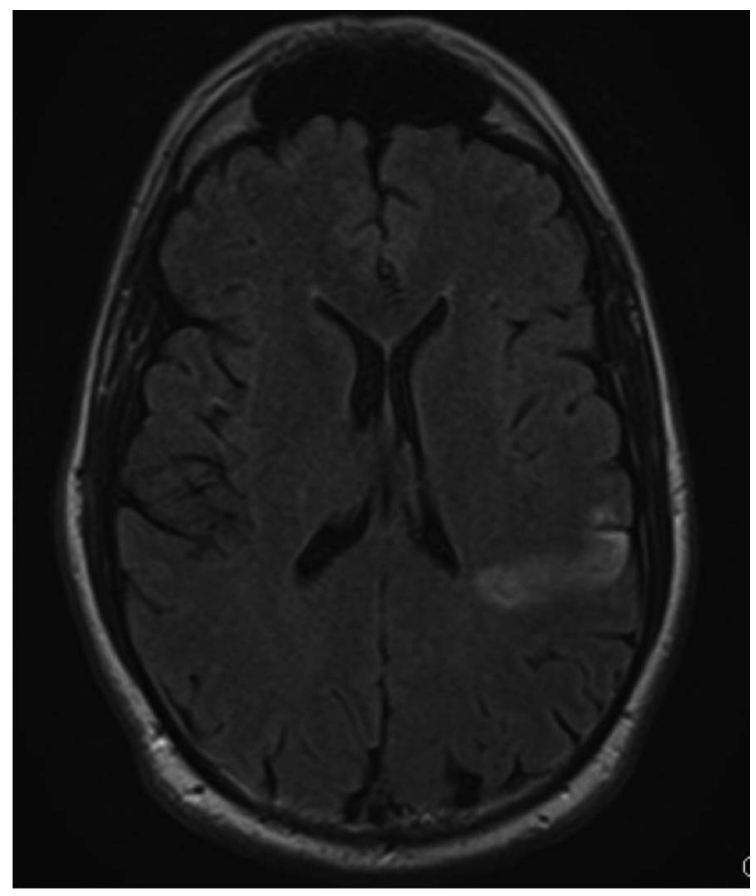

Taste receptors are found in taste buds located on the tongue, soft palate, larynx, epiglottis, uvula, and first third of the esophagus. ${ }^{6} \mathrm{CNs}$ VII, IX, and $\mathrm{X}$ transmit taste information to the brain; the insula and orbitofrontal cortex are the most important areas in the taste sense. ${ }^{7}$

Causes of taste and smell disorders can arise from local or systemic conditions (Table 1). ${ }^{8}$ Certain medications and drugs can also affect an individual's ability to taste and smell (Table 2). ${ }^{9,10}$ Cerebrovascular accidents can alter smell and taste. One study found that patients who suffered a stroke were twice as likely to suffer olfactory impairment. One case report by Moo and Wityk ${ }^{11}$ suggests that bilateral lesions (as present in our patient) may inevitably cause taste and smell deficits-their pa-

\section{Table 1. Causes of Taste and Smell Disorders}

\begin{tabular}{ll}
\hline Local & $\begin{array}{c}\text { Allergic rhinitis Nasal polyps Xerostomic } \\
\text { conditions }\end{array}$ \\
Nutritional & $\begin{array}{l}\text { Vitamin A, B } 6, B_{12} \text { deficiency Zinc or copper } \\
\text { deficiency Chronic renal failure Liver } \\
\text { disease Cancer }\end{array}$ \\
Endocrine & $\begin{array}{l}\text { Diabetes mellitus Hypothyroidism } \\
\text { Kallman's syndrome }\end{array}$ \\
Neurological & $\begin{array}{l}\text { Head trauma Alzheimer's disease Tumors } \\
\text { Vascular lesions }\end{array}$ \\
\hline
\end{tabular}


Table 2. Medications That Cause Taste and Smell Disorders

\begin{tabular}{|c|c|}
\hline Antibiotics & $\begin{array}{l}\text { Azithromycin, ampicillin, ciprofloxacin, } \\
\text { metronidazole }\end{array}$ \\
\hline Anticonvulsants & $\begin{array}{l}\text { Carbamazepine, phenytoin, } \\
\text { topiramate }\end{array}$ \\
\hline Decongestant & Pseudoephedrine \\
\hline Antihistamines & Loratidine \\
\hline Antidepressants & Amitriptyline, clomipramine, doxepin \\
\hline Antihypertensives & $\begin{array}{l}\text { Acetozalamide, enalapril, captopril, } \\
\text { diltiazem, nifedipine, propanolol, } \\
\text { sprinolactone }\end{array}$ \\
\hline Antiarrhythmics & Amiodarone, procainamide \\
\hline Antiinflammatories & Colchicine, dexamethasone \\
\hline Antimanic & Lithium \\
\hline Antineoplastics & Cisplatin, doxorubicin, methotrexate \\
\hline Antiparkinsonism & Levodopa \\
\hline Antipsychotics & Clozapine, trifluoperazine \\
\hline Antithyroids & Methimazole, propylthiouracil \\
\hline Lipid-lowering agents & Lovastatin, pravastatin \\
\hline Muscle relaxants & Baclofen, dantrolene \\
\hline
\end{tabular}

Use of the drugs set in boldface is related to increased incidence of taste and smell disorders.

tient developed symptoms only after he suffered 2 separate strokes involving the insula and adjacent frontoparietal cortices.

Most reports of dysgeusia in the medical literature describe cases that are drug related or caused by postoperative complications. Major causes of dysosmia include head trauma, inflammation (eg, from allergic rhinitis or nasal sinus disease), prior respiratory tract infection, and neurodegenerative disease (eg, Alzheimer disease or Parkinson disease).

While the prevalence of smell and taste disorders increase with age, it is important to investigate medical conditions that may affect a patient's smell or taste. ${ }^{12}$ It is essential to start with a detailed history and physical, including a review of the patient's medication list and their social history, since certain medications, tobacco, and drugs such as cocaine can adversely affect taste and smell. History of diet and oral habits can reveal irritants or issues with dryness of the mouth. If symptoms are intermittent the cause is more likely to be inflammatory than sensorineural. Physical examination should focus on, but not be limited to, the head and neck, looking for obstruction, infection, or inflammation. A neurologic examination should be performed, paying close attention to the CNs. Although in this case the presence of atrial fibrillation was apparent upon physical examination, one could imagine a delay in diagnosis had only a focused examination been done in this patient with no cardiac symptoms.

Tests to consider include a smell identification test, which evaluates 40 microencapsulated "scratch and sniff odorants" to assess CN I deficit. Laboratory studies can be useful to look for infection, nutritional deficiencies, allergy, diabetes mellitus, and thyroid, liver, and kidney disorders. Imaging with computed tomography can be used to evaluate inflammatory disorders of the sinonasal tract as well as bony structures in the ethmoid, cribriform plate, olfactory cleft, and the temporal bone that is close to CN VII. Magnetic resonance imaging is better at defining soft tissue and can be valuable when looking for tumors, infarct, or abscess.

\section{Conclusion}

Our patient presented with a change in taste and smell, which was found to be caused by embolic cerebral infarcts secondary to atrial fibrillation. Altered taste and smell can have a large effect on one's quality of life. It is important to consider local disease, infectious causes, medications, and nutritional, endocrine, and neurological disorders. Treatment should be based on cause and can make a great difference in a patient's quality of life.

\section{References}

1. Taste disorders. NIH publication no. 09-3231A. Bethesda, MD: National Institute on Deafness and Other Communication Disorders; 2009. Available from: http://www.nidcd.nih.gov/health/smelltaste/ pages/taste.aspx/. Accessed May 6, 2014.

2. Smell disorders. NIH publication no. 09-3231. Bethesda, MD: National Institute on Deafness and Other Communication Disorders; 2009. Available from: http://www.nidcd.nih.gov/health/smelltaste/ pages/smell.aspx/. Accessed May 6, 2014.

3. Murphy C, Shubert MS, Cruickshankis KJ, Klein BEK, Klein R, Nondahl DM. Prevalence of olfactory impairment in older adults. JAMA 2002;288: 2307-12.

4. Doty RL. Gustation. Wiley Interdiscip Rev Cogn Sci 2012;3:29-46.

5. Hummel T, Landis BN, Hüttenbrink KB. Smell and taste disorders. GMS Curr Top Otorhinolaryngol Head Neck Surg 2011;10:Doc04.

6. Rosen AM, Roussin AT, Di Lorenzo PM. Water as an independent taste modality. Front Neurosci 2010; $4: 175$. 
7. Rolls ET. Functions of the orbitofrontal and pregenual cingulate cortex in taste, olfaction, appetite and emotion. Acta Physiol Hung 2008;95:131-5.

8. Schiffman SS, Graham BG. Taste and smell perception affect appetite and immunity in the elderly. Eur J Clin Nutr 2000;54(Suppl 3):S54-63.

9. Bromley SM. Smell and taste disorders: a primary care approach. Am Fam Physician 2000;61: $427-36$.
10. Henkin RI. Drug-induced taste and smell disorders. Incidence, mechanisms and management related primarily to treatment of sensory receptor dysfunction. Drug Saf. 1994;11:318-77.

11. Moo L, Wityk RJ. Olfactory and taste dysfunction after bilateral middle cerebral artery stroke. J Stroke Cerebrovasc Dis 1999;8:353-4.

12. Boyce JM, Shone GR. Effects of ageing on smell and taste. Postgrad Med J 2006;82:239-41. 